\title{
Involvement of Carotenoid Cleavage Dioxygenase 4 Gene in Tepal Color Change in Lilium brownii var. colchesteri
}

\author{
Nguyen Thi Lam Hai ${ }^{1 *}$, Jun-ichiro Masuda ${ }^{2}$, Ikuo Miyajima ${ }^{3}$, Nguyen Quoc Thien ${ }^{1}$, \\ Narges Mojtahedi', Michikazu Hiramatsu ${ }^{2}$,Jong-Hwa Kim ${ }^{4}$ and Hiroshi Okubo \\ ${ }^{1}$ Graduate School of Bioresource and Bioenvironmental Sciences, Kyushu University, Fukuoka 812-8581, Japan \\ ${ }^{2}$ Faculty of Agriculture, Kyushu University, Fukuoka 812-8581, Japan \\ ${ }^{3}$ Institute of Tropical Agriculture, Kyushu University, Fukuoka 812-8581, Japan \\ ${ }^{4}$ Department of Horticulture, Kangwon National University, Chuncheon 200-707, Korea
}

Lilium brownii (F. E. Brown) Miellez var. colchesteri $\mathrm{E}$. H. Wilson has a unique characteristic in its flower color, which changes from yellowish-cream to white one day after anthesis. To elucidate the mechanism of flower color change in this species, the content and composition of carotenoids were analyzed during two days of anthesis. The major carotenoids that contributed to the yellowish-cream color of the tepals were lutein, zeaxanthin, and $\beta$-carotene. Analysis showed an obvious decrease in total carotenoid content of the tepal, indicating that the flower color change is caused by the reduction of the total carotenoid content after anthesis. To reveal the factor that controls carotenoid content in the tepals, we isolated carotenoid cleavage dioxygenase 4 (LbCCD4) gene and analyzed the number of $L b C C D 4$ messages by quantitative real-time PCR. The transcription level of $L b C C D 4$ gene increased and reached the maximum level 12 hours after anthesis. The results suggest that the carotenoids in yellow tepals of $\boldsymbol{L}$. brownii var. colchesteri degraded into colorless compounds by carotenoid cleavage dioxygenase and subsequently resulted in white flowers.

Key Words: $\beta$-carotene, carotenoid cleavage dioxygenase 4, Lilium brownii var. colchesteri, lutein, zeaxanthin.

\section{Introduction}

Carotenoids are amongst the most common pigments causing the diversity of flower color in the natural world (Glover, 2009). Carotenoid pigments provide many fruits and flowers with distinctive red, orange, and yellow colors. There are a number of carotenoid-derived aromatic components that attract pollinators and seeddispersal animals. These pigments also play important roles in photosynthesis where they act as accessory lightharvesting substances and as photo-protectants (Bartley and Scolnik, 1995; Davies, 2004, Ronen et al., 1999). Over 700 different kinds of carotenoids have been identified (Britton et al, 2004). Carotenoids are lipidsoluble pigments accumulated in non-photosynthetic chromoplasts of fruits and flowers. Major enzymes involved in the carotenoid biosynthetic pathways have been identified (Cunningham and Gantt, 1998; Hirschberg, 2001; Sandmann, 2001).

Received; April 16, 2012. Accepted; July 21, 2012.

* Corresponding author (E-mail: lamhai1979@yahoo.com).
Recent investigations revealed that carotenoid content in the petals is mainly controlled by the regulation of carotenoid biosynthetic genes. Moehs et al. (2001) reported that 1-deoxy-D-xylulose-5-phosphate synthase and phytoene synthase might be responsible for the color development from pale yellow to deep yellow in marigold petals. In Sandersonia aurantiaca, petals of pale-yellow-flowered cultivars showed a lower expression of phytoene desaturase than those of yellowflowered cultivars, and the expression level tended to be proportionate to the carotenoid accumulation level (Nielsen et al., 2003). Successful genetic modification of catotenoid biosynthetic genes to alter carotenoid content in tissues and change color has been achieved in Brassica napus (Shewmaker et al., 1999), Oryza sativa (Ye et al., 2000), Nicotiana tabacum (Mann et al., 2000; Ralley et al., 2004), Lycopersicon esculentum (Fraser et al., 2002; Rosati et al., 2000), Arabidopsis thaliana (Stålberg et al., 2003), Solanum tuberosum (Morris et al., 2006), and Lotus japonicus (Suzuki et al., 2007).

However, Kishimoto and Ohmiya (2006) found that the formation of the white color in chrysanthemum petals 
was caused neither by down-regulation nor by disruption of the catotenoid biosynthetic genes, but by up-regulation of the carotenoid cleavage dioxygenase gene, which degraded carotenoids into colorless compounds, resulting in white color formation in petals. Carotenoid cleavage dioxygenase genes are also responsible for the differences in carotenoid levels between yellow and white tissues in melon, peach, potato, and Crocus sativus (Brandi et al., 2011; Campbell et al., 2010; Ibdah et al., 2006; Rubio et al., 2008). It can be inferred from these findings that not only carotenoid biosynthetic genes but also carotenase genes are involved in the regulation of carotenoid content in plant tissues. A vast number of carotenase genes categorized into two groups, nine-cisepoxy-carotenoid dioxygenases (NCEDs) and carotenoid cleavage dioxygenases (CCDs), have also been discovered in a variety of plant species (Chernys and Zeewaart, 2000; Mathieu et al., 2005; Schwartz et al., 1997, 2001; Simkin et al., 2004).

Color change of flowers during anthesis is naturally observed in many plants (Weiss, 1991). Studies on the mechanisms of flower color change revealed that alternation of pigment components in the flower tissues is mainly responsible for the color change of flowers. For example, Brunfelsia calycina, a model system for studying flower color change, turns their tepals from dark-purple to completely white within three days of anthesis because of the reduction of anthocyanin concentration during flower development (Vaknin et al., 2005). Kishimoto and Ohmiya (2006) reported that carotenoids in immature chrysanthemum petals were degraded to undetectable levels, resulting in white flowers.

Lilium brownii (F. E. Brown) Miellez var. colchesteri E. H. Wilson is a species endemic to nearly all parts of central China at elevations up to 1,500 meters (McRae, 1998), and its flowers changes from yellowish-cream to white one day after anthesis (Okubo, 2006). This changing color trait is unique to this species and is not observed in any other Lilium species. All hybrid progenies derived from interspecific crosses of L. brownii var. colchesteri with L. formosanum and with $L . \times$ formolongi possess the changing color characteristic (Hai et al., 2012). It seems that the changing color trait is inherited dominantly by the next generation and may be controlled by the genes encoding carotenoid cleavage enzymes; however, the carotenoid compositions and mechanisms of flower color change in L. brownii var. colchesteri have not been studied. In this study, we attempted to analyze the carotenoid composition and content in the tepals during anthesis. We also isolated the gene encoding carotenoid cleavage enzyme to clarify the factor that determines the changing color of flower tepals in L. brownii var. colchesteri.

\section{Materials and Methods}

\section{Plant materials}

Lilium brownii var. colchesteri was collected in Chuncheon prefecture, Kangwon Province, Korea and grown in an open field condition at Kyushu University, Fukuoka, Japan. Each tepal of one flower was collected at twelve-hour intervals divided into five stages: Stage 1 (24 hours before anthesis), Stage 2 (12 hours before anthesis), Stage 3 (at anthesis), Stage 4 (12 hours after anthesis), and Stage 5 (24 hour after anthesis). They were frozen promptly in liquid nitrogen and stored at $-80^{\circ} \mathrm{C}$ for carotenoid and RNA extraction.

\section{Analysis of flower color}

The color of the tepals in each stage was identified according to the Royal Horticultural Society (RHS) Color Chart and their Lightness $\left(L^{*}\right)$ and two chromatic components $a^{*}$ and $b^{*}$ of the Commission International de l' Eclairage (CIE) color system were measured by a portable colorimetric instrument (NF 333; Nippon Denshoku Ind. Co., Ltd., Tokyo, Japan). Color coordinates were the averages of five measurements of each sample.

\section{Determination of carotenoid content and composition}

Carotenoids were extracted from yellow tepals at anthesis (Stage 3) using the method of Nakayama et al. (2006). Approximately $1 \mathrm{~g} \mathrm{FW}$ of tepals was soaked in $\mathrm{CH}_{3} \mathrm{OH}(10 \mathrm{~mL} \times 2)$ and acetone $(10 \mathrm{~mL} \times 2)$ successively. The extract was reduced to an aqueous residue in vacuo before shaking in an equal volume of water and diethyl ether. The ether phase was dehydrated in $\mathrm{Na}_{2} \mathrm{SO}_{4}$ and dissolved in $5 \% \mathrm{KOH} / \mathrm{CH}_{3} \mathrm{OH}$ at room temperature for $3 \mathrm{~h}$. The hydrolyzed extract was added to saturated salt water and mixed with diethyl ether and water. The diethyl ether fraction was dried over $\mathrm{Na}_{2} \mathrm{SO}_{4}$ and evaporated to dryness.

The pigment was dissolved in methanol and analytical HPLC for carotenoids was performed on a C-R3A Chromatopac, an SCL-10Avp system controller, an SPD10Avp UV-Vis spectrophotometric detector, an LC-20 ADvp liquid chromatograph, and CTO-10 Avp column oven (Shimadzu Corp., Kyoto, Japan) using a Cosmosil $5 \mathrm{C}_{18}$ MS-II $4.6 \mathrm{~mm}$ i.d. $\times 250 \mathrm{~mm}$ column (Nacalai Tesque, Kyoto, Japan), with a column temperature of $40^{\circ} \mathrm{C}$ and monitoring at $450 \mathrm{~nm}$. Elution with solvents (solvent A: $90 \% \mathrm{CH}_{3} \mathrm{CN}$; solvent B: ethyl acetate) was performed with a linear gradient from $0-1 \%$ for 0 $10 \mathrm{~min}, 1-65 \%$ for $10-35 \mathrm{~min}, 65-70 \%$ for $35-45 \mathrm{~min}$, and $70-100 \%$ for $45-50 \mathrm{~min}$ of solvent $\mathrm{B}$ at a flow rate of $1 \mathrm{~mL} \cdot \mathrm{min}^{-1}$ at $40^{\circ} \mathrm{C}$.

Additionally, the absorbance spectra at $200-600 \mathrm{~nm}$ of each pigment detected by the HPLC system were recorded with a photodiode array detector.

Peaks 1, 2, and 3 were identified by comparing the retention times and absorbance spectra on HPLC with 
standards (lutein, zeaxanthin and $\beta$-carotene). The carotenoid content was calculated according to the total peak area of HPLC chromatograms at a wavelength of $450 \mathrm{~nm}$ and was expressed as lutein equivalents $[\mu \mathrm{g} / \mathrm{g}$ FW] of the tissue. Carotenoid quantification was performed for three replications.

\section{Standard samples}

The following standard compounds were purchased: zeaxanthin, $\beta$-carotene (Funakoshi Co., Ltd., Tokyo, Japan), and lutein (Sigma-Aldrich Co., St Louis, MO, USA).

\section{RNA isolation and molecular cloning of carotenoid cleavage dioxygenase 4 gene (LbCCD4)}

Total RNA was isolated from the tepal in Stage 3 and purified using an RNeasy Plant Mini Kit combined with RNase-free DNase (Qiagen Japan, Tokyo, Japan). Then, $900 \mathrm{ng}$ of total RNA was reverse transcripted in a $20 \mu \mathrm{L}$ total volume reaction employing a TaKaRa RNA PCR kit (AMV) Ver. 3.0 (Takara, Shiga, Japan) following the manufacturer's instructions. The ratio of the oligo dTadaptor primer: Random 9 mers $4: 1$ was mixed for the reverse transcriptional reaction. PCR was performed using a $1 \mu \mathrm{L}$ aliquot of $10 \times$ diluted cDNA solution in a total volume of $50 \mu \mathrm{L}$ containing $10 \times$ PCR buffer, $0.2 \mathrm{mM}$ of each dNTP, 1.25 Unit TaKara Ex Taq HS polymerase, and $0.2 \mu \mathrm{M}$ of each degenerated primer (Table 3). Amplification was conducted using TaKaRa PCR Thermal Cycler Dice TP-600 (Takara) with one cycle of $2 \mathrm{~min}$ at $94^{\circ} \mathrm{C}$, followed by 40 cycles of $20 \mathrm{~s}$ at $94^{\circ} \mathrm{C}, 20 \mathrm{~s}$ at $54^{\circ} \mathrm{C}$ and $1 \mathrm{~min}$ at $70^{\circ} \mathrm{C}$. The PCR products of an amplified band of about $750 \mathrm{bp}$ were separated by electrophoresis in $1.5 \%(\mathrm{w} / \mathrm{v})$ agarose gels and visualized under UV illumination after staining with ethidium bromide. The amplified fragments were purified by a QIAquick Gel Extraction Kit (Qiagen) and inserted into pGEM-T Easy Vector (Promega; Madison, WI, USA) and transferred into Competent high Escherichia coli DH5 $\alpha$ (Toyobo, Osaka, Japan). After culture, plasmids were extracted using a LaboPass Plasmid Mini Purification Kit (Hokkaido System Science, Hokkaido, Japan) and sequenced with the BigDye Terminator v1.1 Cycle Sequencing Kit (Applied Biosystems, Tokyo, Japan) in an ABI PRISM 310 genetic analyzer (Applied Biosystems).

\section{Expression analysis (real-time PCR)}

Total RNA was isolated from tepals in five stages and treated with RNase-free DNase (Qiagen) according to the manufacturer's protocol using an RNeasy Plant Mini Kit (Qiagen). Then, $1000 \mathrm{ng}$ RNA were reverse transcribed with TaKaRa RNA PCR kit (AMV) Ver. 3.0 (Takara) in $20 \mu \mathrm{L}$ total volume reaction. Aliquots of cDNA solutions were used for real-time PCR using genespecific primers (Table 3) and SYBR Premix Ex Taq (Takara, Kyoto, Japan). Signals were monitored using the Rotor-gene6200 real-time PCR system (Qiagen). The amplification was conducted with one cycle of $10 \mathrm{~s}$ at $95^{\circ} \mathrm{C}$ followed by 45 cycles of $5 \mathrm{~s}$ at $95^{\circ} \mathrm{C}$ and $20 \mathrm{~s}$ at $60^{\circ} \mathrm{C} .18 \mathrm{~S}$ rRNA was surveyed as an internal control using primer pairs reported by Sato et al. (2005). Specific primer pairs for the $L b C C D 4$ gene and 18S rRNA gene were designed (Table 3 ) by referring to the Primer3Plus primer design program (www.bioinformatics.nl/cgi-bin/ primer3plus/primer3plus.cgi). All reactions were run three times in duplicate with one set of cDNA.

\section{Results}

Tepal color of L. brownii var. colchesteri changed from yellow to white one day after anthesis (Fig. 1). The flower color-changing pattern was evaluated by comparison with an RHS Color Chart (Table 1). Tepals at anthesis stage were yellow-green and yellow (151A, 1A), then turned pale yellow (11D) $12 \mathrm{~h}$ later and finally became white (155D). The chromaticity of the tepals, expressed by $L^{*}, a^{*}$, and $b^{*}$ values, indicating lightness, redness, and yellowness, respectively, showed the correlation between the anthesis stages and color tone. Yellowness ( $b^{*}$ value) tended to decrease with the time after anthesis, whereas vividness $\left(C^{*}\right.$ value) decreased to the white color threshold. The $L^{*}$ value (lightness of the color) and $a^{*}$ value increased simultaneously with the decreased of $b^{*}$ value during anthesis. White tepals that could be detected by the naked eye started when the $L^{*}$ value was higher than 80 .

Three major peaks were detected by HPLC in the extract from tepals of L. brownii var. colchesteri at the anthesis stage (Fig. 2), and were identified as lutein, zeaxanthin, and $\beta$-carotene according to the retention time and maximum absorbance spectrum by scanning wavelengths from 200 to $600 \mathrm{~nm}$. The amounts of each

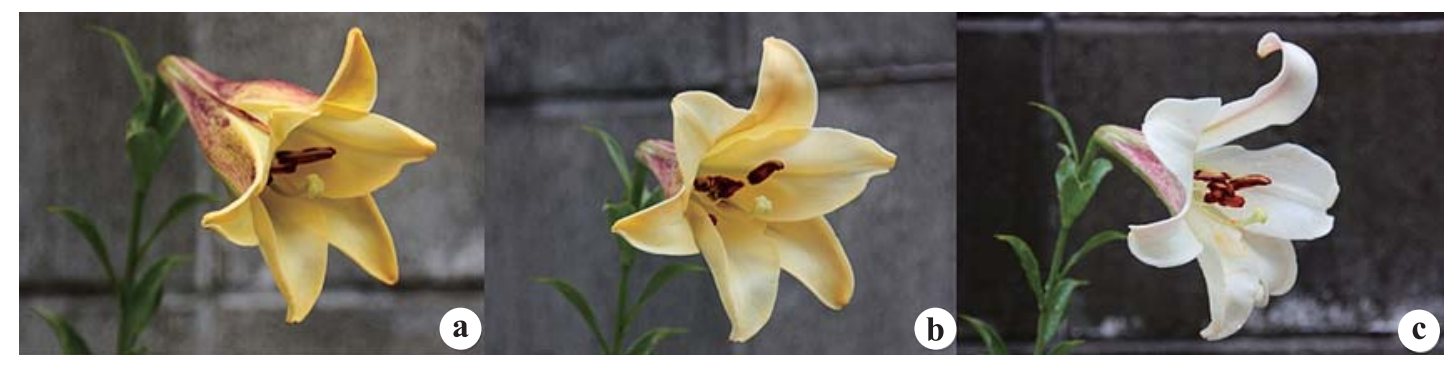

Fig. 1. L. brownii. var. colchesteri flower color changes from yellow to white during anthesis in field. a, b, c are fully opened flowers at anthesis, 12 hours after anthesis and 24 hours after anthesis, respectively. 
Table 1. Color of L. brownii var. colchesteri tepals determined by RHS Color Chart and colorimetric instrument.

\begin{tabular}{lcccrc}
\hline \hline & Stage 1 & Stage 2 & Stage 3 & Stage 4 & Stage 5 \\
\hline RHS Color Chart & Yellow green 151A & Yellow green 151A & Yellow 1A & Yellow 11D & White 155D \\
$L^{*}$ & $48.40 \pm 0.09^{z}$ & $58.88 \pm 0.27$ & $74.93 \pm 0.37$ & $83.27 \pm 0.09$ & $84.28 \pm 0.14$ \\
$a^{*}$ & $-23.83 \pm 1.11$ & $-9.28 \pm 0.06$ & $-7.75 \pm 0.08$ & $-1.05 \pm 0.06$ & $-0.44 \pm 0.07$ \\
$b^{*}$ & $30.42 \pm 3.30$ & $32.00 \pm 0.02$ & $22.79 \pm 0.61$ & $9.90 \pm 0.21$ & $5.65 \pm 0.20$ \\
$C^{*}$ & $38.64 \pm 3.48$ & $33.32 \pm 0.07$ & $24.07 \pm 0.61$ & $9.95 \pm 0.22$ & $5.66 \pm 0.04$ \\
\hline
\end{tabular}

${ }^{\mathrm{z}} \operatorname{Mean} \pm \operatorname{SE}(\mathrm{n}=5)$.

$L^{*}$ : Lightness $(0=$ black; $100=$ white $)$.

$a^{*}, b^{*}$ : Shifts from negative to positive value, indicating that the color shifts from bluish-green to purplish-red and from blue to yellow, respectively. $C^{*}$ : Vividness of color, $C^{*}=\left(a^{* 2}+b^{* 2}\right)^{1 / 2}$.

Table 2. Change of carotenoid content in L. brownii var. colchesteri tepals during anthesis.

\begin{tabular}{lrrrrc}
\hline \hline & \multicolumn{5}{c}{ Carotenoid content $(\mu \mathrm{g}$ lutein equiv./g FW) } \\
\cline { 2 - 6 } & \multicolumn{1}{c}{ Stage 1 } & \multicolumn{1}{c}{ Stage 2 } & \multicolumn{1}{c}{ Stage 3 } & \multicolumn{1}{c}{ Stage 4 } & \multicolumn{1}{c}{ Stage 5 } \\
\hline Lutein & $13.44 \pm 1.25^{z}$ & $10.68 \pm 1.23$ & $9.92 \pm 0.99$ & $2.08 \pm 0.16$ & $0.99 \pm 0.08$ \\
Zeaxanthin & $25.59 \pm 2.08$ & $20.29 \pm 1.37$ & $19.79 \pm 0.53$ & $3.19 \pm 0.44$ & $1.70 \pm 0.29$ \\
$\beta$-Carotene & $4.53 \pm 0.71$ & $4.58 \pm 0.27$ & $0.97 \pm 0.20$ & $0.87 \pm 0.03$ & $0.74 \pm 0.16$ \\
Total & $43.56 \pm 4.04$ & $35.75 \pm 2.88$ & $30.67 \pm 1.72$ & $6.14 \pm 0.64$ & $3.10 \pm 0.53$ \\
\hline
\end{tabular}

Mean $\pm \operatorname{SE}(n=3)$.

Table 3. Degenerate primers and gene-specific primers used in this study.

\begin{tabular}{llll}
\hline \hline & Genes & Primers & \multicolumn{1}{c}{ Sequences } \\
\hline Degenerate primers & CCD4 & Forward & TACATCCGCAACGGTCCCAAC \\
& & Reverse & GTGTATCATGTTGAACCCCGG \\
Gene-specific primers for real-time PCR & CCD4 & Forward & ACTCTCTTCCGGTTCGACAAG \\
& & Reverse & TCCATCGGCTTCATTACCATC \\
& 18S rRNA & Forward & GAAAGACGAACAACTGCGAAAG \\
& & Reverse & CGGCATCGTTTATGGTTGAG \\
Gene-specific primers for RACE & 5'RACE & Reverse & TGTGCACATGGCGTGAGCAGAGG \\
& 3'RACE & Forward & CCGATGGACATGGTGCTTGGTGGTG \\
\hline
\end{tabular}

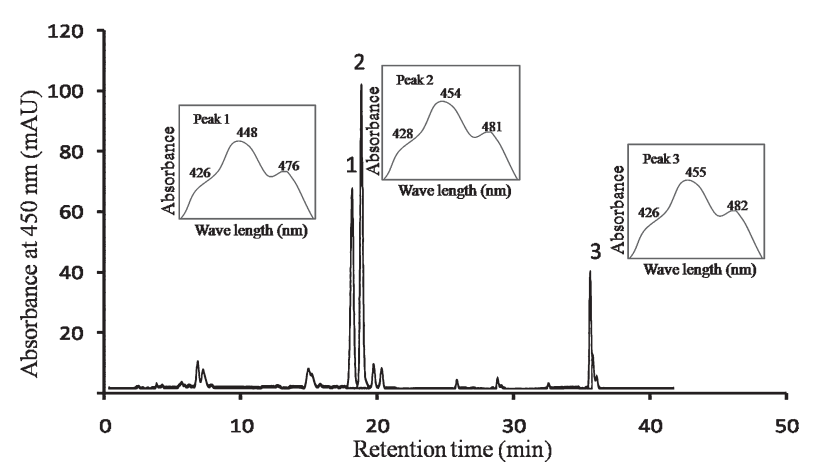

Fig. 2. HPLC analysis of carotenoids extracted from tepals of L. brownii var. colchesteri at anthesis. Absorbance spectra from 200 to $600 \mathrm{~nm}$ of each peak are presented in the boxes, and number in the boxes shows the wavelength $(\mathrm{nm})$. Peaks: 1 . lutein, 2. zeaxanthin, 3. $\beta$-carotene.

pigment were determined in five stages of anthesis (Table 2). Zeaxanthin and lutein accounted for approximately $65 \%$ and $30 \%$ of total carotenoid content in tepals of Stage 3, respectively. Total carotenoids decreased markedly between Stage 3 and Stage 4 (about 5 times) showing the color change in the tepals, although high amounts of carotenoids were detected in yellow tepals in early anthesis stages and in the fully opened flower stage. Small amounts of carotenoids were detected in white tepals $24 \mathrm{~h}$ after anthesis. It can be inferred from this result that the decrease of carotenoid content in tepals during anthesis causing the change from yellow to white of lily tepals.

Full-length cDNA of the carotenoid cleavage dioxygenase 4 gene was isolated from tepals at the anthesis stage (Stage 3). A gene fragment of the $L b C C D 4$ gene was first cloned using RT-PCR with degenerated primers. Furthermore, full-length cDNA was obtained by $5^{\prime}$ and $3^{\prime}$-RACE using gene-specific primers. The nucleotide sequence of full $L b C C D 4$ contains $2149 \mathrm{bp}$, including a 5 '-non-coding region of $35 \mathrm{bp}$, a complete ORF of $1503 \mathrm{bp}$ corresponding to 501 amino acids, and a 3'-non-coding region of $611 \mathrm{bp}$. The sequence of LbCCD4 was submitted to GenBank with accession number AB733097. The deduced amino acid sequence 
of $L b C C D 4$ showed $94 \%$ identity with chrysanthemum $\times$ morifolium and clustered with those of $C C D 4 s$ (Fig. 3). Sequence analysis revealed that $L b C C D 4$ contained four highly conserved histidine residues that have been previously described as typical ligands of a non-haem iron cofactor required for dioxygenase activity (Schwartz et al., 1997) (Fig. 4).

Expression of carotenoid cleavage dioxygenase 4 gene at five stages during anthesis was compared (Fig. 5). Transcription level of LbCCD4 increased to the maximum level $12 \mathrm{~h}$ after anthesis and maintained a high level in the following stage. In other words, the expression level of $L b C C D 4$ was relatively low in yellow tepals and was markedly high in pale yellow and white tepals, indicating that the carotenoids in yellow tepals were degraded by $L b C C D 4$ translated products to form colorless compounds, resulting white tepals of $L$. brownii var. colchesteri $24 \mathrm{~h}$ after anthesis.

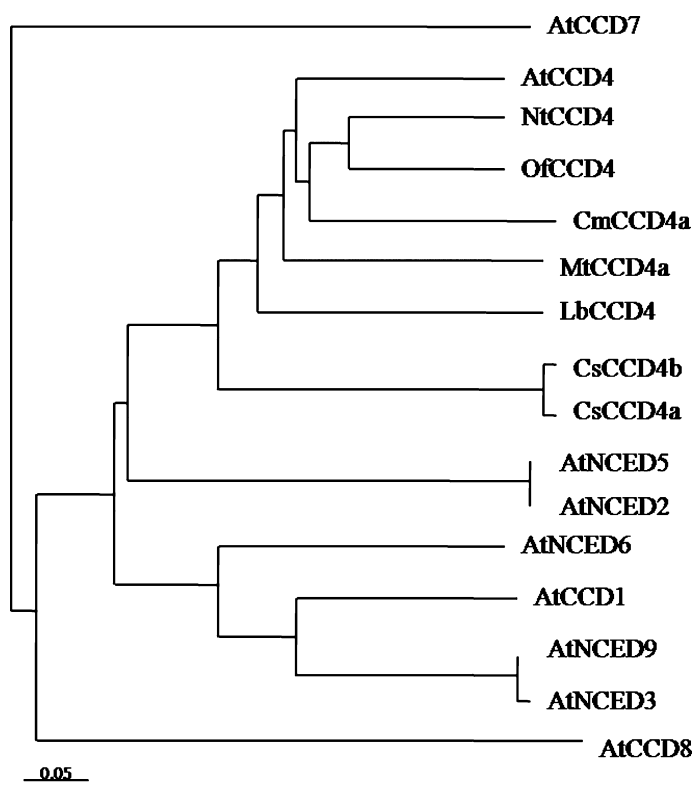

Fig. 3. Phylogenetic tree of $C C D$ genes constructed by the neighborjoining method using full-length deduced amino acid sequences. The protein sequences were clustered using the program ClustalW (http://embnet.vital-it.ch/software/ClustalW.html). The GenBank accession numbers for the sequences are as follows: AtCCD1 (Arabidopsis thaliana, NP191911), AtNCED2 (Arabidopsis thaliana, NP193569), AtNCED3 (Arabidopsis thaliana, NP188062), AtNCED5 (Arabidopsis thaliana, NP174302), AtNCED6 (Arabidopsis thaliana, NP189064), AtNCED9 (Arabidopsis thaliana, NP177960), AtCCD7 (Arabidopsis thaliana, NP182026.1), AtCCD8 (Arabidopsis thaliana, NP195007.2), OfCCD4 (Osmanthus fragrans, ABY60887.1), CsCCD4a (Crocus sativus, ACD62476.1), CmCCD4a (Chrysanthemum $\times$ morifolium, BAF36656), AtCCD4 (Arabidopsis thaliana, NP193652), CcCCD4 (Citrus clementina, ABC26011), MdCCD4 (Malus $\times$ domestica, ABY47995). MtCCD4a (Medicago truncatula, XP003612460), CsCCD4b (Crocus sativus, ACD62477), NtCCD4 (Nicotiana tabacum, AEI61930.1).

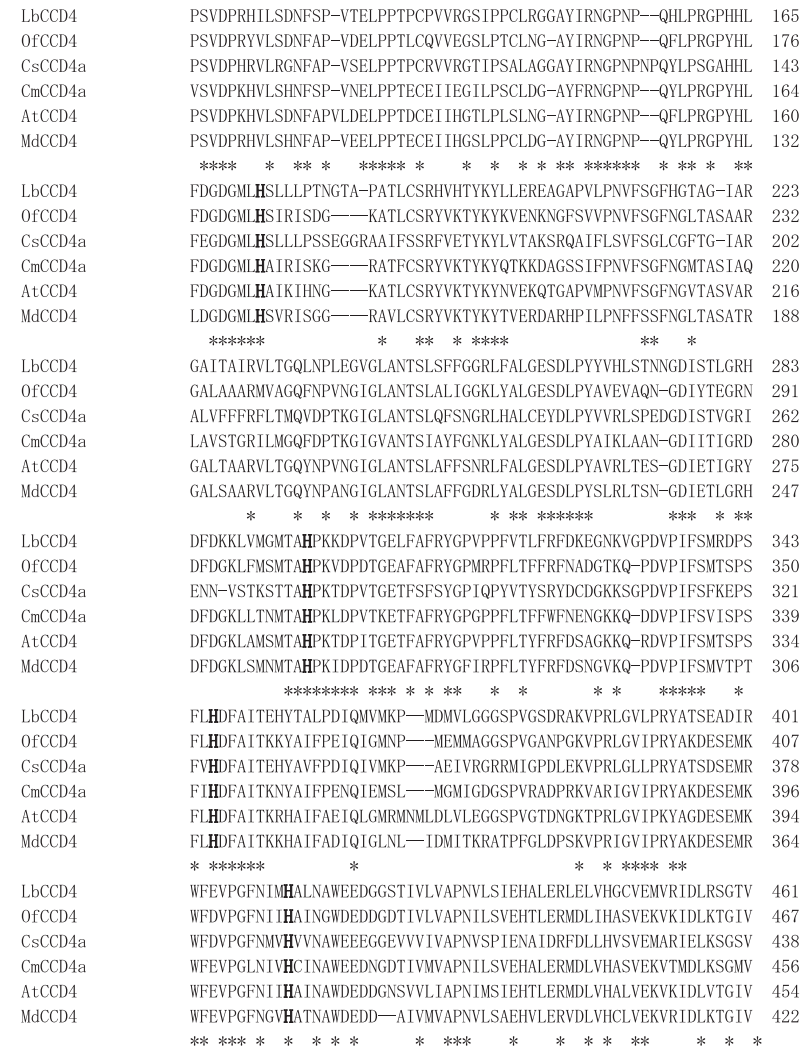

Fig. 4. Comparison of the highly conserved region of LbCCD4 and other carotenoid cleavage dioxygenase 4 enzymes. Asterisks indicate completely identical amino acid residues among six species. Bold letters indicate the four iron-ligating histidines. The protein sequences were aligned using the program ClustalW (http://embnet.vital-it.ch/software/ClustalW.html). The Gen-Bank accession numbers for the sequences are as follows: OfCCD4 (Osmanthus fragrans, ABY60887.1), CsCCD4a (Crocus sativus, ACD62476.1), CmCCD4a (Chrysanthemum $\times$ morifolium, BAF36656), AtCCD4 (Arabidopsis thaliana, NP193652), MdCCD4 (Malus $\times$ domestica, ABY47995).

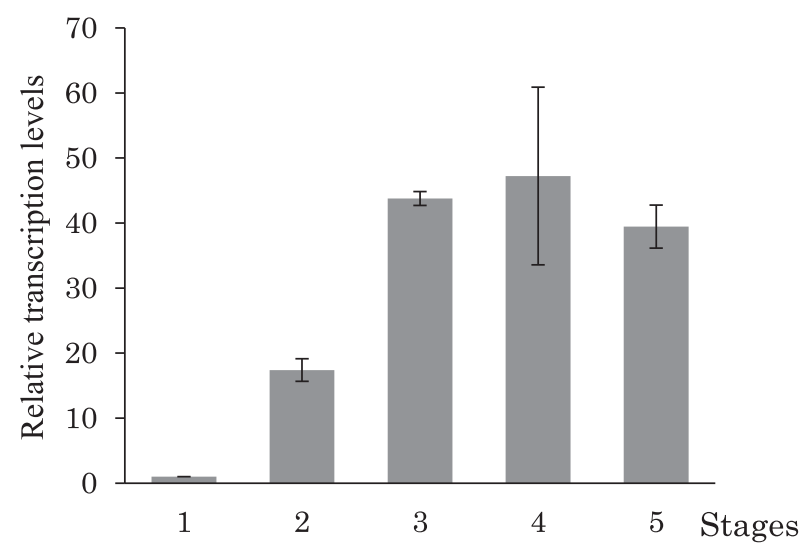

Fig. 5. Relative expression of $L b C C D 4$ in flower tepals of $L$. brownii var. colchesteri during anthesis. 24 hours before anthesis (Stage 1), 12 hours before anthesis (Stage 2), anthesis (Stage 3), 12 hours after anthesis (Stage 4), 24 hours after anthesis (Stage 5). Quantitative real-time RT-PCR analysis was performed in triplicate using specific primers, and the amplified 18S rRNA was used as an internal control. Mean values $\pm \mathrm{SE}$ are shown. 


\section{Discussion}

In the present study we identified carotenoid fingerprints in floral tissue of L. brownii var. colchesteri and revealed that the principal carotenoid components are lutein, zeaxanthin, and $\beta$-carotene. This mixture of three carotenoid compounds causes the bright yellow color of the flowers by the stage of full blooming and distinguishes this species from other closely related species such as L. longiflorum and L. formosanum whose flowers show only white tepals. Carotenoid composition in flower tepals in the genus Lilium has been studied by several authors. Six kinds of carotenoids, $\beta$-carotene, cryptoxanthin, echinenone-like carotenoid, zeaxanthin, capsanthin, and capsorubin, have been frequently identified in flower tepals of more than 20 Lilium species (Banba, 1968). Re-investigation by Deli et al. (1998) showed that the tepals of tiger lily (L. lanciflorum) contained only $\beta$-carotene derivatives, such as antheraxanthin and capsanthin. In Asiatic hybrid lily, yellow and red tepal cultivars accumulated high amounts of carotenoids, mostly antheraxanthin and violaxanthin derivatives, whereas cultivars with pink and white tepals accumulated small amounts of carotenoids (Yamagishi et al., 2010). The distinctive carotenoid compositions revealed in the genus Lilium demonstrated that carotenoids are typical characteristics that closely depend on the plant species. Accumulation information on flower pigments will give valuable insights contributing to the ability to breed new lily cultivars.

Among the three pigments detected in the tepals, zeaxanthin and lutein were highly accumulated and accounted for about $95 \%$ of total carotenoid content, and nearly $90 \%$ of these two major pigments were catabolized 24 hours after flowering. In contrast, most $\beta$-carotene was degraded before flowering and was maintained in a tiny amount in tepals during anthesis retention (Table 2). These results indicate that zeaxanthin and lutein mainly contribute to the yellow flowers of L. brownii var. colchesteri and degradation of these pigments is responsible for flower color change. Lutein and zeaxanthin are the predominant carotenoids in photosynthetic plant tissues and play a critical role in light-harvesting complex assembly and in protecting the photosynthetic apparatus from the adverse effects of excessive light (Demmig and Bjorkman, 1987; Pogson et al., 1996). In addition, they are also precursors to a range of norisoprenoids possessing aromatic properties. The shifting color from yellow to white is usually attributed to the strategy of flower plants to attract pollinating insects by making the floral tissue stand out against a background of vegetation; however, since L. brownii var. colchesteri is a self-incompatible species (Shimizu, 1971) that produces no viable seeds in any self- or cross-pollinations (Saruwatari, 2009; Hai et al., 2012), the changing color trait has no function in pollinator attraction in this lily; that is, its function in the degradation of carotenoids into colorless volatile compounds could only be elucidated from the strong fragrance formation in tepals by one day after anthesis.

Ohmiya et al. (2006) clearly demonstrated the effect of $\mathrm{CmCCD} 4 \mathrm{a}$ activity on carotenoid accumulation in chrysanthemum petals: $C m C C D 4 a$ expression was higher in white-flowered chrysanthemum genotypes than in their respective yellow-pigmented counterparts, and white petals turned yellow after the RNAi construct was introduced to white petal cultivars. A hypothesis of this study was whether a similar mechanism is a factor controlling carotenoid accumulation in flower tepals of L. brownii var. colchesteri. Transcription level in the CCD4 gene was elevated in white tepals of L. brownii var. colchesteri whose carotenoid content was reduced to an almost undetectable level. Amino acid sequence comparison revealed that $L b C C D 4$ exhibited the highest similarity to $\mathrm{CmCCD} 4 a$, implying that the enzyme of the $L b C C D 4$ gene may have the same function in carotenoid dioxygenase as that of $\mathrm{CmCCD} 4 \mathrm{a}$, resulting in the disintegration of carotenoids in the tepals.

Recently, CCD4 enzymes were characterized from several crops and shown to have a major impact on organ pigmentation. For instance, $C C D 4$ expression was higher in white-fleshed potato and peach cultivars than in their yellow-fleshed counterparts (Brandi et al., 2011; Campbell et al., 2010). Yamamizo (2000) revealed that the CCD4 gene was involved in the degradation of chloroplast-type carotenoids responsible for the formation of white petals of Ipomoea obscura. Studies by Rubio et al. (2008) on carotenoid dioxygenase in $C$. sativus showed that the CCD4 family contained at least two forms of the gene with different structures, expression patterns and genome position, and their encoded enzymes showed different substrate specificity. Taken together, these results imply that high expression of the $C C D 4$ gene is always associated with the reduction of carotenoids in tissues. Therefore, although not conclusive, the expression of the $L b C C D 4$ gene might be the main reason for the degradation of carotenoids after anthesis, causing the change from yellow to white flowers in L. brownii var. colchesteri.

Although lutein and zeaxanthin contents between Stage 1 and 2 have a higher degradation rate than those between Stage 2 and 3 (Table 2), the expression level of LbCCD4 in Stage 3 was higher than that in Stage 2 (Fig. 3). These results infer that the degradation of carotenoid before anthesis seems not correspond to the expression pattern of $L b C C D 4$. The evidence shown in this study is not adequate to judge whether the $L b C C D 4$ gene is the key factor controlling the flower color change in L. brownii var. colchesteri. Referring to the report of Ohmiya et al. (2009) on the role of CmCCD4a in Chrysanthemum by using an RNA interference (RNAi) technique to inhibit the expression of $C m C C D 4 a$ for yellow flower formation, we suggest that the RNAi technique is appropriate for further investigation into the 
role of the LbCCD4 gene in the color change characteristic in L. brownii var. colchesteri. The inactivating of the $L b C C D 4$ gene during anthesis may result in yellow flowers of $L$. brownii var. colchesteri if LbCCD4 is the main factor controlling the flower color change in this lily species.

\section{Acknowledgements}

We sincerely thank Dr. Masayoshi Nakayama (NARO Institute of Floricultural Science) for kindly analyzing the carotenoid pigments using a photodiode array detector.

\section{Literature Cited}

Banba, H. 1968. Pigments of lily flower. II. Survey of carotenoid. J. Japan. Soc. Hort. Sci. 37: 368-378.

Bartley, G. E. and P. A. Scolnik. 1995. Plant carotenoids: pigments for photoprotection, attraction, and human health. Plant Cell 7: $1027-1038$.

Brandi, F., E. Bar, F. Mourgues, G. Horváth, E. Turcsi, G. Giuliano, A. Liverani, S. Tartarini, E. Lewinsohn and C. Rosati. 2011. Study of 'Redhaven' peach and its white-fleshed mutant suggests a key role of CCD4 carotenoid dioxygenase in carotenoid and norisoprenoid volatile metabolism. Plant Biol. 11: 24-39.

Britton, G., S. Liaaen-Jensen and H. Pfander. 2004. Carotenoids Handbook. Birkha user Verlag, Basel.

Campbell, R., L. J. M. Ducreux, W. L. Morris, J. A. Morris, J. C. Suttle, G. Ramsay, G. J. Bryan, P. E. Hedley and M. A. Taylor. 2010. The metabolic and developmental roles of carotenoid cleavage dioxygenase 4 from potato. Plant Physiol. 154: 656664.

Chernys, J. T. and J. A. D. Zeevaart. 2000. Characterization of the 9-cis-epoxycarotenoid dioxygenase gene family and the regulation of abscisic acid biosynthesis in avocado. Plant Physiol. 124: 343-353.

Cunningham, J. F. X. and E. Gantt. 1998. Genes and enzymes of carotenoid biosynthesis in plants. Ann. Rev. Plant Physiol. Plant Mol. Bio. 49: 557-583.

Davies, K. M. 2004. An introduction to plant pigments in biology and commerce. p. 1-22. In: K. M. Davies (ed.). Plant pigments and their manipulation. Blackwell Publishing, Oxford.

Deli, J., P. Molnár, Z. Matus, G. Tóth, A. Steck and H. Pfander. 1998. Isolation and characterization of 3,5,6-trihydroxycarotenoids from petals of Lilium tigrinum. Chromatographia 48: 27-31.

Demmig, B. and O. Bjorkman. 1987. Comparison of the effect of excessive light on chlorophyll fluorescence $(77 \mathrm{~K})$ and photon yield of $\mathrm{O}_{2}$ evolution in leaves of higher plants. Planta 171: 171-184.

Fraser, P. D., S. Romer, C. A. Shipton, P. B. Mills, J. W. Kiano, N. Misawa, R. G. Drake, W. Schuch and P. M. Bramley. 2002. Evaluation of transgenic tomato plants expressing an additional phytoene synthase in a fruit-specific manner. Proc. Natl. Acad. Sci. 99: 1092-1097.

Glover, B. J. 2009. The diversity of flower color: how and why. Int. J. Design \& Nature and Ecodynamics 4: 211-218.

Hai, N. T. L., M. Hiramatsu, J. Masuda, J-W. Kim and H. Okubo. 2012. Interspecific hybrids production between Lilium brownii var. colchesteri and its close relatives by ovary slice culture. J. Japan. Soc. Hort. Sci. 81: 191-197.

Ibdah, M., Y. Azulay, V. Portnoy, B. Wasserman, E. Bar, A. Meir, Y. Burger, J. Hirschberg, A. A. Schaffer, N. Katzir, Y. Tadmor and E. Lewinsohn. 2006. Functional characterization of $C m C C D 1$, a carotenoid cleavage dioxygenase from melon. Phytochemistry 67: 1579-1589.

Hirschberg, J. 2001. Carotenoid biosynthesis in flowering plants. Plant Bio. 4: 210-218.

Kishimoto, S. and A. Ohmiya. 2006. Regulation of carotenoid biosynthesis in petals and leaves of chrysanthemum (Chrysanthemum morifolium Ramat.). Physiol. Plant. 128: 437-447.

Mann, V., M. Harker, I. Pecker and J. Hirschberg. 2000. Metabolic engineering of astaxanthin production in tobacco flowers. Nat. Biotech. 18: 888-892.

Mathieu, S., N. Terrier, J. Procureur, F. Bigey and Z. Gunata. 2005. A carotenoid cleavage dioxygenase from Vitis vinifera $\mathrm{L}$.: functional characterization and expression during grape berry development in relation to C13-norisoprenoid accumulation. J. Exp. Bot. 56: 2721-2731.

McRae, E. A. 1998. Lilies. Timber Press, Portland.

Moehs, C. P., L. Tian, K. W. Osteryoung and D. DellaPenna. 2001. Analysis of carotenoid biosynthetic gene expression during marigold petal development. Plant Mol. Bio. 45: 281-293.

Morris, W. L., L. J. M. Ducreux, P. D. Fraser, S. Millam and M. A. Taylor. 2006. Engineering ketocarotenoid biosynthesis in potato tubers. Meta. Eng. 8: 253-263.

Nakayama, M., M. Miyasaka, T. Maoka, M. Yagi and N. Fukuta. 2006. A carotnoid-derived yellow Eustoma screened under blue and ultraviolet lights. J. Japan. Soc. Hort. Sci. 75: 161165.

Nielsen, K. M., D. H. Lewis and E. R. Morgan. 2003. Characterization of carotenoid pigments and their biosynthesis in two yellow flowered lines of Sandersonia aurantiaca (Hook.). Euphytica 130: 25-34.

Ohmiya, A., K. Sumitomo and R. Aida. 2009. 'Yellow Jimba' suppression of carotenoid cleavage dioxygenase $(\mathrm{CmCCD} 4 \mathrm{a})$ expression turns white chrysanthemum petals yellow. J. Japan Soc. Hort. Sci. 78: 450-455.

Ohmiya, A., S. Kishimoto, R. Aida, S. Yoshioka and K. Sumitomo. 2006. Carotenoid cleavage dioxygenase ( $\mathrm{CmCCD} 4 \mathrm{a}$ ) contributes to white color formation in chrysanthemum petals. Plant Physiol. 142: 1193-1201.

Okubo, H. 2006. History of Lilium brownii var. colchesteri in Japan. Sci. Bill. Fac. Agr. Kyushu Univ. 61: 145-163 (In Japanese with English abstract).

Pogson, B., K. A. McDonald, M. Truong, G. Britton and D. DellaPenna. 1996. Arabidopsis carotenoid mutants demonstrate that lutein is not essential for photosynthesis in higher plants. Plant Cell 8: 1627-1639.

Ralley, L., E. M. A. Enfissi, N. Misawa, W. Schuch, P. M. Bramley and P. D. Fraser. 2004. Metabolic engineering of ketocarotenoid formation in higher plants. Plant J. 39: $477-$ 486.

Ronen, G., M. Cohen, D. Zamir and J. Hirschberg. 1999. Regulation of carotenoid biosynthesis during tomato fruit development: Expression of the gene for lycopene epsilon-cyclase is downregulated during ripening and is elevated in the mutant delta. Plant J. 17: 341-351.

Rosati, C., R. Aquilani, S. Dharmapuri, P. Pallara, C. Marusic, R. Tavazza, F. Bouvier, B. Camara and G. Giuliano. 2000. Metabolic engineering of $\beta$-carotene and lycopene content in tomato fruit. Plant J. 24: 413-419.

Rubio, A., J. L. Rambla, M. Santaella, M. D. Gomez, D. Orzaez, A. Granell and L. Gomez-Gomez. 2008. Cytosolic and plastoglobule-targeted carotenoid dioxygenases from Crocus sativus are both involved in beta-ionone release. J. Biol. Chem. 283: 24816-24825. 
Sandmann, G. 2001. Carotenoid biosynthesis and biotechnological application. Arch. Biochem. Biophys. 385: 4-12.

Saruwatari, H. 2009. Studies on precocious flowering of Lilium formosanum and its introduction into other Liilum species. PhD thesis, Kyushu University, Fukuoka.

Sato, A., K. Saitou and H. Okubo. 2005. Estimation of actin and 18S rRNA as internal controls of RNA in hyacinth (Hyacinthus orientalis L.). J. Fac. Agr. Kyushu Univ. 50: 103-108.

Schwartz, S. H., X. Qin and J. A. Zeevaart. 2001. Characterization of a novel carotenoid cleavage dioxygenase from plants. J. Biol. Chem. 276: 25208-25211.

Schwartz, S. H., B. C. Tan, D. A. Gage, J. A. D. Zeevaart and D. R. McCarty. 1997. Specific oxidative cleavage of carotenoids by VP14 of maize. Science 276: 1872-1874.

Shewmaker, C. K., J. A. Sheehy, M. Daley, S. Colburn and D. Y. Ke. 1999. Seed specific overexpression of phytoene synthase: increase in carotenoids and other metabolic effects. Plant $\mathrm{J}$. 20: $410-412$.

Shimizu, M. 1971. Lilies of Japan (In Japanese). Seibundoshinkosha, Tokyo.

Simkin, A. J., S. H. Schwartz, M. Auldridge, M. G. Taylor and H. J. Klee. 2004. The tomato carotenoid cleavage dioxygenase 1 genes contribute to the formation of the flavor volatiles $\beta$ ionone, pseudoionone, and geranylacetone. Plant J. 40: 882-
892.

Stålberg, K., O. Lindgren, B. Ek and A. S. Höglund. 2003. Synthesis of ketocarotenoids in the seed of Arabidopsis thaliana. Plant J. 36: 771-779.

Suzuki, S., M. Nishihara, T. Nakatsuka, N. Misawa, I. Ogiwara and S. Yamamura. 2007. Flower color alteration in Lotus japonicus by modification of the carotenoid biosynthetic pathway. Plant Cell Rep. 26: 951-959.

Vaknin, H., A. Bar-Akiva, R. Ovadia, A. Nissim-Levi, I. Forer, D. Weiss and M. Oren-Shamir. 2005. Active anthocyanin degradation in Brunfelsia calycina (yesterday-todaytomorrow) flowers. Planta 222: 19-26.

Weiss, M. R. 1991. Floral color changes as cues for pollinators. Acta Hort. 288: 294-298.

Yamagishi, M., S. Kishimoto and M. Nakayama. 2010. Carotenoid composition and changes in expression of carotenoid biosynthetic genes in tepals of Asiatic hybrid lily. Plant Breed. 129: 100-107.

Yamamizo, C., S. Kishimoto and A. Ohmiya. 2010. Carotenoid composition and carotenogenic gene expression during Ipomoea petal development. J. Exp. Bot. 61: 709-719.

Ye, X., S. Al-Babili, A. Klöti, J. Zhang, P. Lucca, P. Beyer and I. Potrykus. 2000. Engineering the provitamin A ( $\beta$-carotene) biosynthetic pathway into (carotenoid-free) rice endosperm. Science 287: 303-305. 